\title{
RECREATION AND SIMULATION OF PREINDUSTRIAL FLOUR PROCESSES IN THE MARGIN OF RIVERS
}

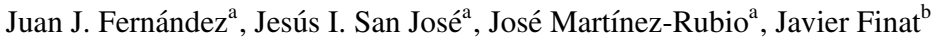 \\ ${ }^{\text {a }}$ Laboratory of Architectural Photogrammetry (LFA) \\ ETS Arquitectura, Universidad de Valladolid \\ Avda Salamanca s/n, 47014, Valladolid, Spain \\ (juanjo, lfa,jmrubio)@ega.uva.es \\ ${ }^{\mathrm{b}}$ Modelado, Biomecánica y Visualización Avanzada del Patrimonio (MoBiVAP) \\ Parque Científico de la Universidad de Valladolid \\ Paseo de Belén 11, 47010, Valladolid, Spain \\ jfinat@agt.uva.es
}

Commission V, WG V/4

KEY WORDS: Cultural Heritage, Augmented Reality, Preindustrial activities, Simulation of processes

\begin{abstract}
:
Manufacture and preindustrial activities have configured infrastructures and commercial development along several centuries. Both regional economic and social environment of the present days can be seen as a consequence of the secular interaction between available physical resources and social tissue along our history. Since ancient times, the economy of Castile and Leon has been based on livestock and agriculture, predominantly represented by cattle and large cereal extensions. Thus, flour industry plays an important role which has been reflected along the Medieval and Renaissance ages in a network of preindustrial installations involving mills and "aceñas" (which are also water-powered mills but set up as larger plants containing different kinds of grinders). In this work we have performed an architectural surveying of a bunch of those large-scale abandoned installations which precede the development of the flour factories that brought the industrial era. Our case of use focuses on the aceñas placed in a strech of the Duero river, between Tordesillas and Toro (Spain). Our work includes the virtual reconstruction of mechanisms and a simulation of the processes that milling involves by using the transformation of hydrodynamical forces into mechanical power. Furthermore the architectural container, our development allows the visualization of the milling machinery running, enriched with a simulation of some aspect of the involved hydrodynamic aspects.
\end{abstract}

\section{INTRODUCTION}

From the late nineties of 20th century there is an increasing interest about Industrial Cultural Heritage (ICH, in the successive) which has been extended to Pre-Industrial and Technological Cultural Heritage (PITCH) involving Renaissance and beyond. The PITCH involves large rural zones which were articulated in the past around transformation activities which have modified the physical and social landscape. It is necessary to engage citizens, business and communities to discover and be proud of its own identity. So, they will be able of maintaining, supporting and developing related activities which are specific of each zone, because each zone has its own history. The different social and economic agents must be protagonists of an integrated discourse, because they are the responsible of revitalizing their environment.

Intangible traditions involve to uses, costumes, routes, local celebrations ... whose origins are sometimes forgotten. Their preservation must be attached to real and/or virtual representations able of illuminating some keys for understanding them. Pre-industrial activities are linked to an organization of regional production and distributions in local markets. In particular, these activities were organized around small centers acting as intermediate between producers and consumers, as it occurs with the transformation of grain in flour. Hence, the architectural surveying of pre-industrial installations provides a physical and objective support to develop an integrated discourse able of incorporating different interpretations, and their cultural, economic and historical extensions which are strongly related between them. Thus, to begin with we provide a coarse description of some basic principles linked to a representation of architectural industrial heritage as a narrative tool.

In this work we introduce a methodology for surveying PITCH linked to flour mills along large rivers in a small zone of Castilla y Leon (Spanish region in the North plateau). Nevertheless the local character, our methodology can be extended to similar zones in other zones near to rivers or old commercial routes. Our goal is multiple and displays several complementary aspects such as contextualize the environment and the fabrics, architectural surveying of buildings, and simulation of processes involving grain milling. The main novelty concerns to the integration of all of them under a Mobile Augmented Reality (MAR) application. This integration is necessary for the mise-in-value of active usually neglected, and for their exploitation by local communities with the assistance of SMEs linked to the production of multimedia contents for Cultural Heritage.

Contextualize the surveyed object is very often neglected, and when it appears, it involves mainly to academic aspects linked to architectural styles or technological solutions. Instead, we propose another view which is based in the interactive discovery of physical landscape, historical, social and technological issues which provide the keys to understand the surveyed buildings as a whole in a common and integrated framework. With this approach we intend to explain how the pre-industrial and manufacture activities configure a local landscape, commercial routes and market activities which contribute to organize the socio-economic environment, besides architectural aspects of buildings and/or technological solutions. Obviously, this is long-term approach; thus, in this work, we present a preliminary contribution which sketches 
only some meaningful elements to be integrated and developed in following work to be accomplished.

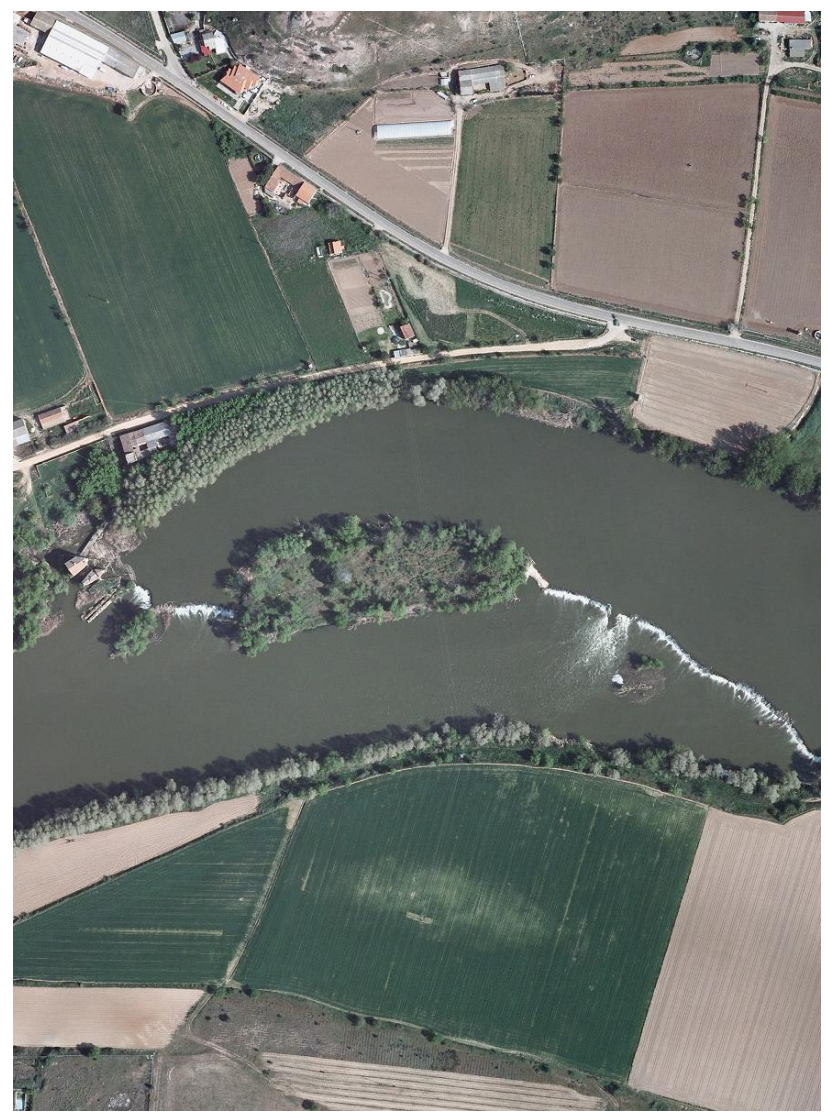

Figure 1: Environmental approach from aerial views

The recreation of disappeared realities linked to PITCH, requires the introduction of virtual and augmented reality (VR/AR in the successive) models able of explaining the original context and how technologies were coupled between them. Along last years, there is an increasing development of VR/AR models and tools to understand Cultural Heritage contents, and its projection to enhance the feeling of an European citizenship. The European Commission is aware of recent advances of these technologies; currently, they are promoting the development of cooperation which is focused around the development of ICT innovative creative activities as a development motor for different stake holders. Main agents are integrated by multimedia industries (SMEs, e.g.) and academic partners.

Unfortunately, it is meaningful that along the FP6 of EU there is only a supported project CONSIST which is related to Industrial Cultural Heritage; in addition, this connection is a tangential one, because it is focused towards the Comparison of conservation materials and strategies for sustainable exploitation of immovable industrial cultural heritage made of iron and steel. This topic has no relation with the development of rural zones, neither the integration of less developed areas or the recovery of local and/or regional activities. In other words, it does not contribute to balance or to develop a specific cultural development.

More recently and along the FP7 of the EC, there have been several initiatives which are linked with particular phenomena linked to corrosion phenomena, damaged materials or another aspects linked to life of materials. Doubtless, these initiatives are very interesting for developing a collaboration between academic and industrial partners, including SMEs linked to Engineering Materials. However, they have no relation with the promotion of a citizenship based in the mutual knowledge and the mise-in-value of the own Cultural Heritage

Our aim is exactly the opposite one. We intend to promote a rediscovery of pre-industrial activities in less developed regions as a cohesion factor in the past, which explains the old and almost disappeared network of relationships between near zones. In this way and from a better knowledge and enjoy of these traditions, we intend to identify them as a way of articulating a richer social tissue, perform their reprojection towards the next future and to reinforce the consciousness of citizenship as participant in a joint project, and not a simple spectator of very large scale initiatives.

To illustrate this program, we have developed a case-of-use which is focused to explain the workflow of flour processes performed by large preindustrial installations, such as Aceñas, which are built in stone with a typical shape given as a ship with a countercurrent prow; inside they contain are a large flour mill for grinding up the grain. They are very robust installations, which have been able of surviving large floods and they have worked till the nineteen century near to large rivers. Currently they are abandoned and it is not easy to understand workflows involving not only mechanical aspects, but also the intra-history around these objects.

To perform our modeling we have combined different aspects involving image- and range-based Architectural surveying, preindustrial devices for grinding as an antecedent of more advanced solutions in Mechanical Engineering, and a multilevel approach to their integration by using Computer Graphics simulations. In the next future, we shall incorporate more advanced rendering techniques for more realistic experiences by using advanced tools of Computational Dynamics of Fluids, in order to reproduce the behavior of involved mechanisms.

According to this scheme, we have organized our paper in four additional sections involving a description of landscape and architectural surveying which have been used for grinding grains fabrics, and their integration in a common model; this model provides a support to superimposed additional contents as successive layers. Next, we display a $3 \mathrm{D}$ reconstruction of the waterwheels and related mechanisms which were based in a reconversión of hydraulic power in mechanical power for flour mill. The performed reconstruction poses several problems involving simulation of mechanisms a some additional rendering issues which are discussed in an additional section. Last, we perform a discussion of results and present some conclusions and challenges to be solved in the next future.

\section{ARCHITECTURAL SURVEYING OF PRE-INDUSTRIAL INSTALLATIONS}

In this section we give a description of methods and techniques which have been performed for an architectural surveying of flour mills of abandoned installations along the Duero river from Tordesillas (Valladolid, Spain) to Toro (Zamora, Spain). Figure 1 shows the right choice for location of the flour mill of Pisones (Zamora) having into account the hidrographical characteristics of the river. Sometimes, installations are not enough secure and the visit is not always possible. Furthermore, most people are unable of understanding vestiges, identify components and articulate all of them in a coherent representation. It is necessary to understand the context, describe some assets (including basic principles of mechanisms) and the architecture as a common framework for the right interpretation of this pre-industrial landscape. 
Some recent related initiatives involve to surveying and fostering urban creative zones of interest from the ICH viewpoint. It is convenient to have an overall project strategy, which we have adapted from the methodology proposed in (Creative City Challenges: Industrial heritage in fostering urban creative zones, 2014). According to this approach, we select three stages labeled as (1) architectural mapping, (2) mental mapping, and (3) dialog and strategy / idea-development (in this work we are not concerned with description of potential and dialog among landowners). The goals to be achieved in the first stage relative to Architectural Mapping concern to (Creative City Challenges: Industrial heritage in fostering urban creative zones, 2014):

1. Identify, describe and evaluate areas with (pre-)industrial cultural heritage;

2. Register significant characteristics and assess the architectural qualities for further analysis;

3. Make material and results available for the upcoming phases

After identifying the object of study (mills of grain actuated by hydraulic power), next task concerns to registration aspects. Nevertheless, the lack of sources, the methodology proposed in (Creative City Challenges: Industrial heritage in fostering urban creative zones, 2014) can be extrapolated to our case of study. By following the flowchart proposed in page 9 , this section is related to the subphase 2 (Description) which concerns to fieldwork and evaluation of available sources, involving to registering areas and markers in the field.

In our case, some additional troubles arise from scarce and disperse documentary sources for pre-industrial Cultural Heritage, and sometimes unaccessible places where pre-industrial installation are located; very often physical and/or technological resources are almost hidden by vegetation or partially destroyed by river floodings. Thus, the task to be performed has some archaeological component which is linked to the discovery and interpretation of PITCH vestiges. To achieve this goal, it is crucial to describe the context involving physical and cultural landscape, on one side, and human and technological resources on the other hand.

The understanding of relationships between landscape and resources in everyday life is performed on an architectural representation. Its interpretation makes possible to identify the role which is played by different social agents along large temporal periods. So, a better knowledge of interrelations between landscape and resources through its spatial representation, will allow the acknowledgement and mise-in-value of almost forgotten intangible resources. These topics concern mainly to the second stage which involve to mental mapping which is presented in the fourth section. All of them are linked to activities, routes, and different expressions of creativity involving economic and technological activities, and architectural surveying provides.

Very often the river course has been locally modified to obtain the necessary volume of flow for moving mills with hydraulic forces. Mill fabrics are usually located where the speed is highest, which includes non-convex "vertices" (opposite to meanders), which increase the dynamical forces to be used. To achieve this goal, keelshaped stone constructions have been performed at such nonconvex vertices, which reorient the flow volume along narrow stepped channels where the machinery is located. Aerial views are very useful, because they provide a global representation justifying the choice for the best locations of flour mills in our case.

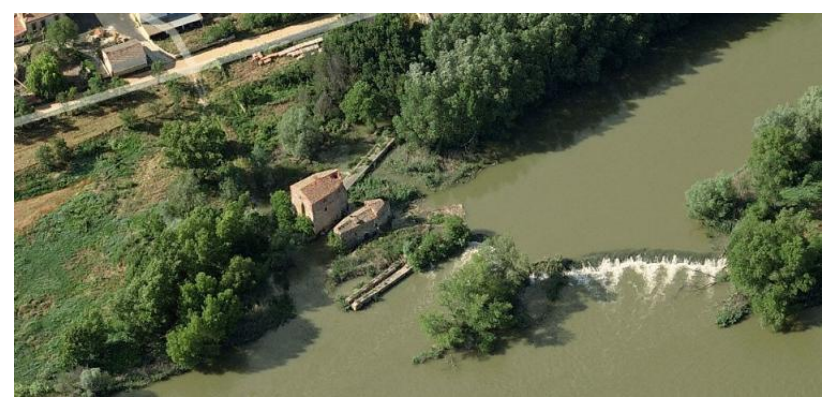

Figure 2: Aerial view of Pisones Dam

Figure 2 provides a nearer approach which displays the relative location of some installations between them.

After contextualizing the environment from hydrographic viewpoint, it is necessary to identify the main characteristics of the environment. Very often, it is hidden by vegetation or partially destroyed by human actions and/or river floodings. Thus, aerial views do not provide the necessary information to give a local representation of the fabrics. Sometimes, fallen trees and other accidents make impossible to introduce laser scanners near to the objects to be surveyed. In these cases, it is only possible to take different views and try of performing a manual survey of the most outstanding characteristics. Figure 3 illustrates an approximate representation obtained of an almost inaccessible fabric ${ }^{1}$ whose real look can be seen in the frontal view of the figure 4. In absence of a complete covering of the whole fabrics building, the integration of the captured information poses relevant challenges for a complete surveying of architectural objects.

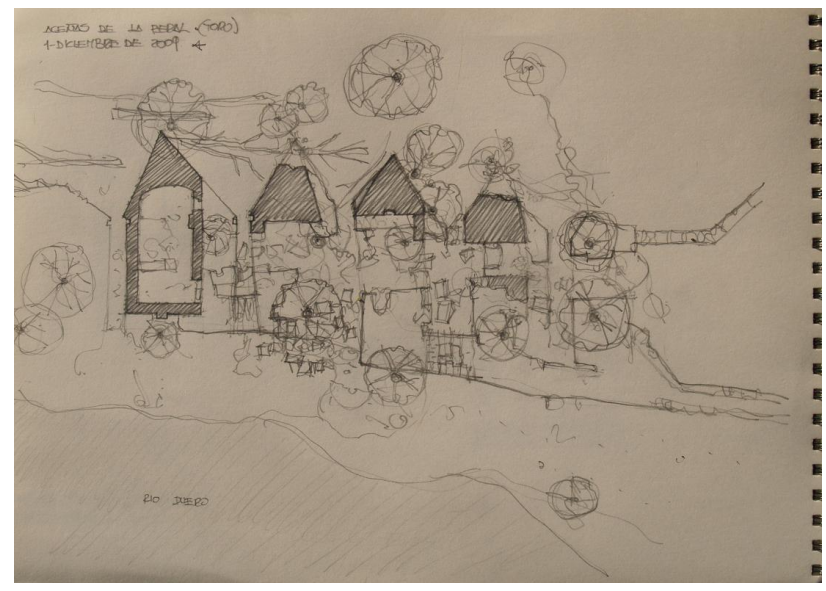

Figure 3: Hand sketch of almost unaccessible mill fabrics

The construction of flour fabrics from milling of corn generates transformations in landscape which involves not only to the installations but to the network of paths and roads around the building, and a complex social structure involving offices and relationships between different agents. Currently, the abandon of old fabrics, a partial destruction by human and natural actions, and their coverage by vegetation poses additional challenges to recover these pre-industrial environments and to understand their role in the spatial articulation between 13th and 19th centuries.

\section{WATERWHEELS AND RELATED MECHANISMS}

Waterwheels and extensions of Archimedes screws have been used from the second century B.C. for the conversion of hydraulic power in mechanical energy. In presence of a large flow volume

\footnotetext{
${ }^{1}$ Sketch performed by Jesús I. San José
} 


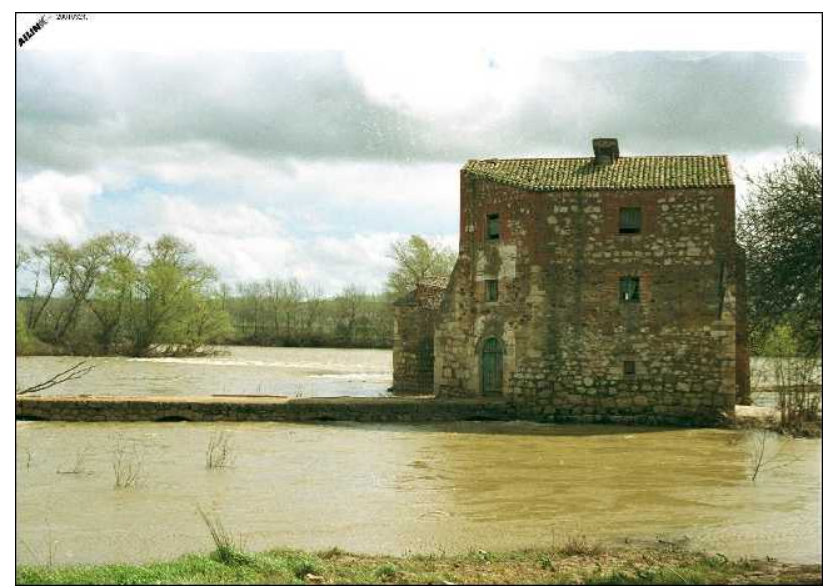

Figure 4: Frontal view of Pisones flour fabric

or for low height, simple solutions based on some of both procedures provide amenable solutions which can be combined between them and adapted to different environments. However, in presence of high ground differences or unequal flow volumes, the problem becomes much harder.

Waterwheels are commonly used in Mediterranean (greek, roman, arabian) cultures and they are flourished in the medieval age following different formats with peculiar local adaptations, as it appears in medieval Christian Spanish kingdoms of Castilla and Aragón, also. A compendium and extension of all these contributions which incorporates a large amount of contributions arising from civil Italian and Spanish engineers of late Renaissance can be found at (Keller, 1998)

Perhaps the most sophisticated device for high ground differences along the sixteenth century is performed in Toledo by the Italian engineer Giovanni Torriani (Cremona 1500, Toledo 1585) called Juanelo Turriano in Spanish language. His goal was to lift the water of Tajo river by saving a high of ninety meters with a complicated orography and a large variety of slopes. The main technological problem to be solved was the conversion of a circular motion in rectilinear motion along the long path connecting the river course with the Alcazar and the city of Toledo. The original documentation of Torriani's solution is unfortunately lost and the last vestiges of civil engineering were destroyed at the end of the nineteenth century; in fact their solution was abandoned at the early 17 th century because nobody was able of performing the right maintenance. Currently, there are two hypotheses about transmission principles, but we have not a complete understanding of his solution ${ }^{2}$

The Spanish word Aceña arises from an Arab expression which means hydraulic wheel. Hence, the terminology involves to the engineering principles which transform the hydraulic energy in mechanical energy for grinding any kind of corn by means of mills mechanisms. The coupling between wheels and axis in the perpendicular plane, plays the same role as the more modern turbines; both of them follow the same mechanical principles which have been used from more than eight centuries ago. Indeed, there are several types of wind and water mills, with their corresponding mechanisms to generate a multiplicative effect performed by grinding mechanisms.

Depth and flow volumes impose constraints for different kinds of mills. In a very simplified way, there are two main kinds of mechanical devices for conversion of hydraulic forces in mechanical

\footnotetext{
${ }^{2} \mathrm{~A}$ very nice simulation can be seen in https://www youtube. com/watch?v=MwU6m9tjM2A
}

efforts: For low depth and scarce flow volumes, it is necessary to use horizontal mechanisms based in wheels which are displaced by the water action. Hydraulic efforts for this second class of mechanisms are lesser than those which are required for vertical mechanisms. Horizontal motion is transmitted to a vertical axis which is coupled with another horizontal mechanisms. These simple mechanical considerations impose structural constraints about the architectural design which is necessary to achieve to obtain the right anchorage and a better performance of mechanical devices.

In our case, and nevertheless their morphological diversity, we have found both types of mechanisms. Vertical mechanisms are common in narrow channels between the keel-shaped stone constructions; in some cases, lifted water was used for another purposes linked to adjacent water deposits which were constructed as regulator elements or for fishing activities, e.g.. Horizontal mechanisms require less volume flow and they can be used in a complementary way in minor constructions or as an alternative solution when the water flow was not enough to move large vertical waterwheels. Figure 5 illustrates the basic horizontal mechanism used along the 16th century and before.

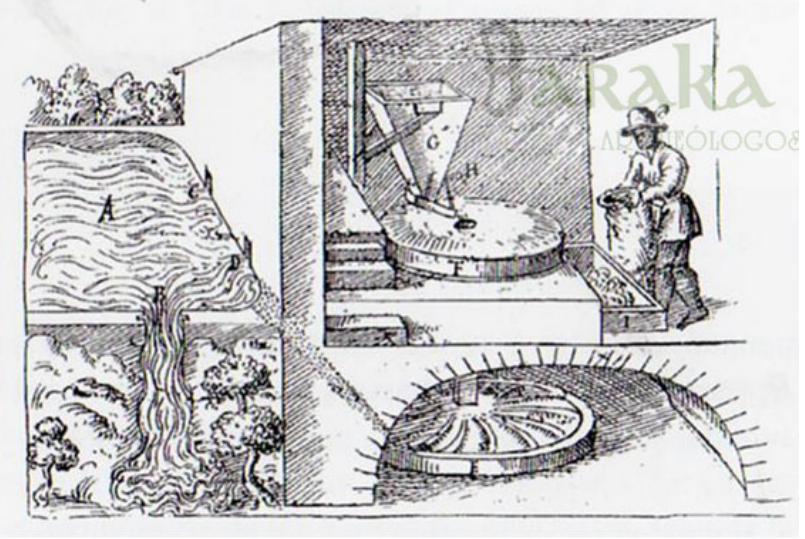

Figure 5: Horizontal mills or rodeznos

For low ground differences and nevertheless the unequal flow volume, the problem is easier because it suffices to perform a transformation between rotational efforts linked to wheels located in different planes. In this kind of mechanisms, the transmission depends on the relationships between diameters of wheels located at different planes and gear mechanisms connecting them, which is the case of mills activated by mechanical energy arising from hydraulic power. Nevertheless the architecture of installations must be enough robust to support dynamical forces arising from the water and embedded mechanisms in civil constructions.

From a larger socio-economic viewpoint, grinding processes have promoted and conditioned the development of villages which have become regional centers for transformations of agrarian exploitations. Some of these villages (Tordesillas, Toro) become the market centers for the distribution and resulting relationships have configured the physical landscape and a large amount of intangible $\mathrm{CH}$ along last seven centuries. For instance, Figure 6 is a gravure of the 19th century illustrating the architecture of mill fabrics adjacent to the Duero river passing throught Tordesillas.

Most installations for conversion of grains in flour by using water mills are composed by a dam, and a collection of buildings where the grinding processes are performed by using different mechanisms. Dams are constructed transversally to the river course, usually in non-convex corners where the flow is faster. Civil constructions are constructed to make smaller the the water courant 


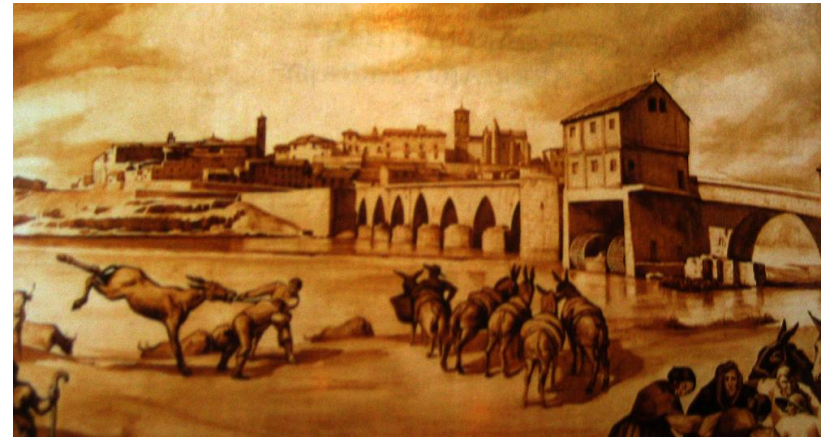

Figure 6: Gravure of Tordesillas including flour fabrics

width and increase its speed; the resulting channeling in narrow corridors allows to transform the hydraulic power in a force acting along a horizontal ("rodezno" in Spanish language) or a vertical wheel ("noria" in Spanish language). The water action turns a wheel of palettes, and the circular motion is transmitted to another elements which are connected by means of a vertical or, alternately, a horizontal axis towards another wheels which move a conical grinder or crushing mechanism ("muela superior" in Spanish language) contained in a larger conical hopper which is connected with a smaller deposit ("tolva" in Spanish language) to refill flour sacks. The iteration of grinding processes would allow to develop a coarse-to fine result for resulting flour.

The basic mechanical principle is given by the transformation of hydraulic power in mechanical energy through a collection of coupled mechanisms which are disposed in perpendicular planes to optimize mechanical efforts (it is a very simple application of vector product in Mathematics). The right relative disposition of mechanisms and the design of dentate wheels to improve the multiplicative effects result in more efficient grinding processes. If there would be necessary, grinding process can be iterated to obtain finer flour. Figure 7 displays the current status of a wheel which has been used till the 19th century in regard with more modern uses as electricity production, also.

Risks linked to flooding (due to sudden changes in flow volume), and efforts supported by the corresponding transmission mechanisms require a very robust architecture. This requirement is translated in the construction of very robust docks (keel-shaped constructions) for re-orienting the river courant, able of supporting floods, and in civil engineering constructions to accommodate the machinery. Furthermore, there are some auxiliary constructions such as footbridges for connecting consecutive docks, and buildings to store grain, floor, or other materials linked with other tasks. In some cases, floor mills have been used as sawmills by coupling other mechanisms to cut out the wood. More recently and along the 19th century some of these installations have been used to produce electricity, where mechanical principles are similar ones to the described above.

\section{AN INTEGRATED SIMULATION OF FLOUR GRINDING}

In this section we illustrate perform a simplified representation of grinding process, contextualize the mechanical model inside a simplified representation of fabrics. In this way, we intend to provide a journey to a pre-industrial past going from the above realistic representation of the outdoor towards an increasingly virtualized of the indoor.

Resources based in VR/AR provide a mental mapping of physical space and technological resources involved in the flour production from grinding grain activities. According to the scheme

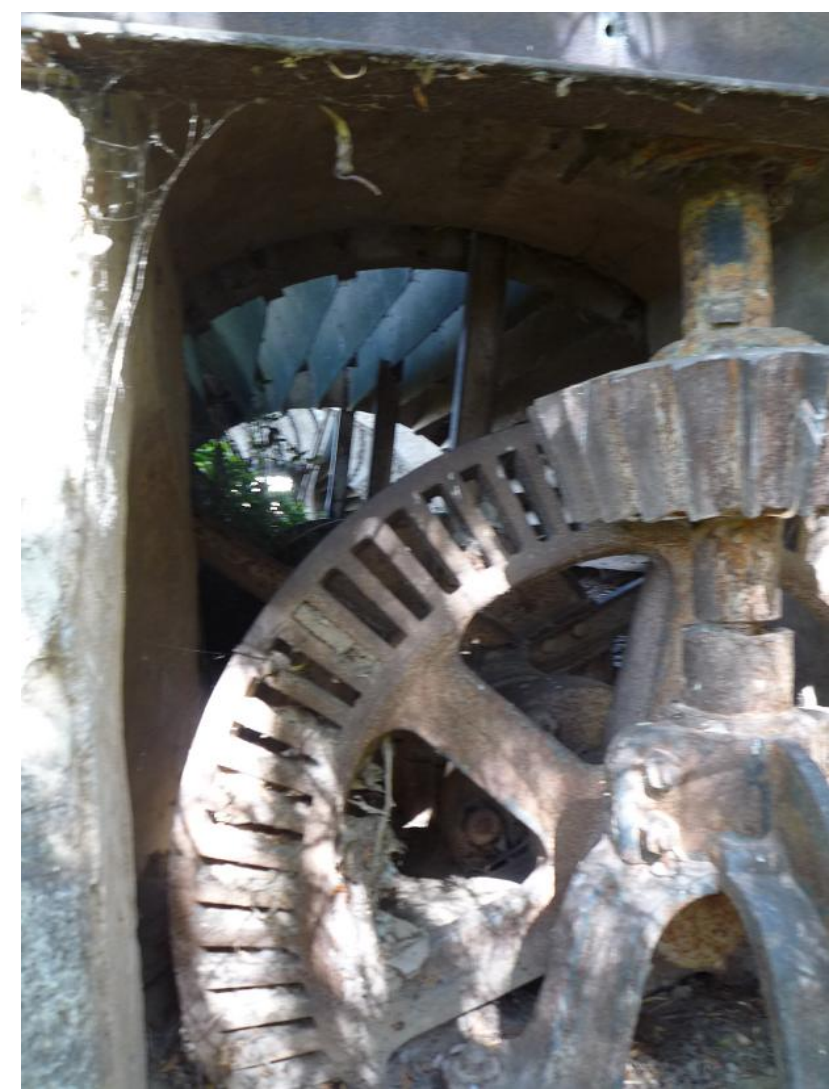

Figure 7: Original mechanism of waterwheels

proposed in (Creative City Challenges: Industrial heritage in fostering urban creative zones, 2014), the main purposes are the following ones:

1. Visibility, gathering, and identification of patterns (places and themes)

2. Generation of a report, and a map to make the material and results available for the upcoming phases.

3. Involvement and management, the focused dialog, further exploration and testing patterns.

In particular, we are mainly concerned with some aspects relative to the first item, which is the most meaningful from the academic viewpoint. In fact the report as a collection of materials relative to precedent sub-phases has been published already (I.SanJosé and J.J.Fernández-Martín, 2010), and the availability of maps with gathered patterns ordered after place; hence, its dissemination is a competence of Public Regional Administration to whom belong the materials. On the other hand, third point involves to the role to be played by different social agents in collaboration with professional in charge of promoting dissemination and the articulation of initiatives linked to the mise-in-value of PITCH. To ease the mise-in-value of these spaces it is necessary to develop some urgent interventions of conservation and restoration, because the current status is near to the ruin even for the best preserved buildings. Figure 8 illustrates the indoor of one the best preserved buildings.

To illustrate flour grinding processes we use very simplified VR models. Their incorporation to interactive AR applications on mobile devices follows the same methodology which has been 


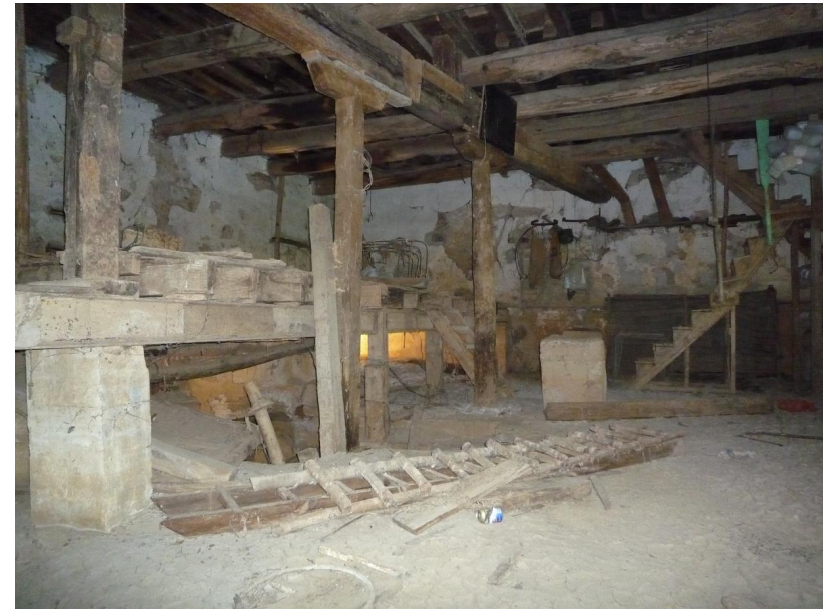

Figure 8: Current state of indoor scenario

exposed in (Delgado et al., 2013). The main purpose is to improve the visibility, perform an open gathering, and identify some of the most common patterns involving the physical space and involved technologies. In this way, we intend to ease a greater acquittance with pre-industrial processes involving grinding grain and its conversion in flour. Far from being a consequence of conversion of hydraulic power in mechanical energy, the main goal for dissemination purposes would must be described in terms of a transformation of human work and its incidence on the nearest environment.

After a first approach to the local environment, it is convenient to have a three-dimensional model which can allow a more secure and interactive visit. To achieve these goals, we have used terrestrial and image- and range-based approaches, which we have completed with virtual models to include some details which are unfortunately lost. The architectural surveying includes different aspects concerning to location, outdoor and indoor visualization. Furthermore documentation aspects, we have developed 3D virtual models which can be displayed in videos to acquire a more faithful representation of the architectural representation. A static view of the waterwheel mechanism embedded into a simplified representation of building can be seen in 9 .

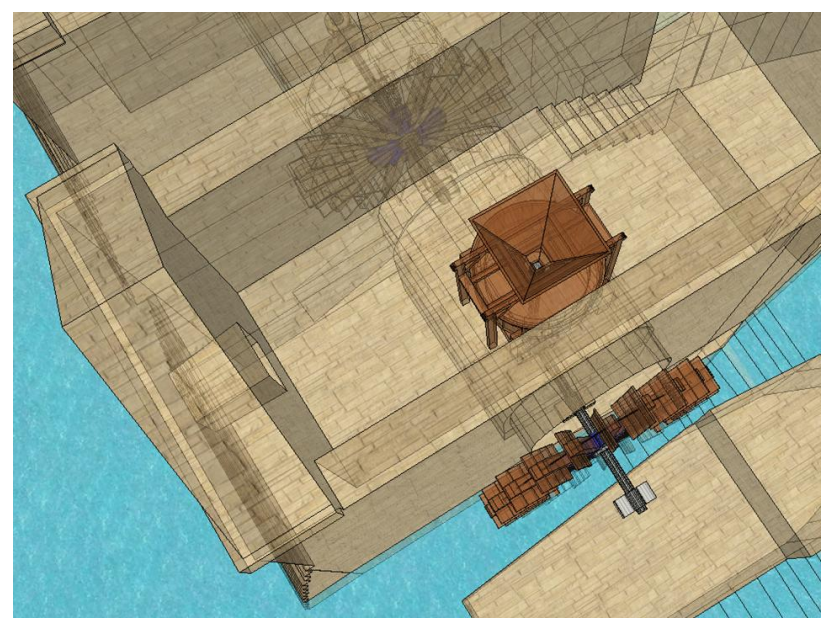

Figure 9: Simplified representation of the mill motion with inserted machinery

\section{EVALUATION AND DISCUSSION}

The most difficult problem is the integration of the architectural surveying of reconstructed environments with working mechani- cal devices in a realistic way. This task involves to a more realistic representation of Fluid Mechanics which is far beyond of the objectives of the work presented here. In the meantime, we restrict ourselves to display a model with different levels of details, involving the building and a decoupled representation of inserted mechanisms. The operation of coupled mechanisms involve to several wheels which are connected between them with orthogonal axes; its dynamical representation requires a careful design of gears, able of providing a realistic representation of motion which is illustrated in figure 10 , by deleting the surrounding architectural environment.

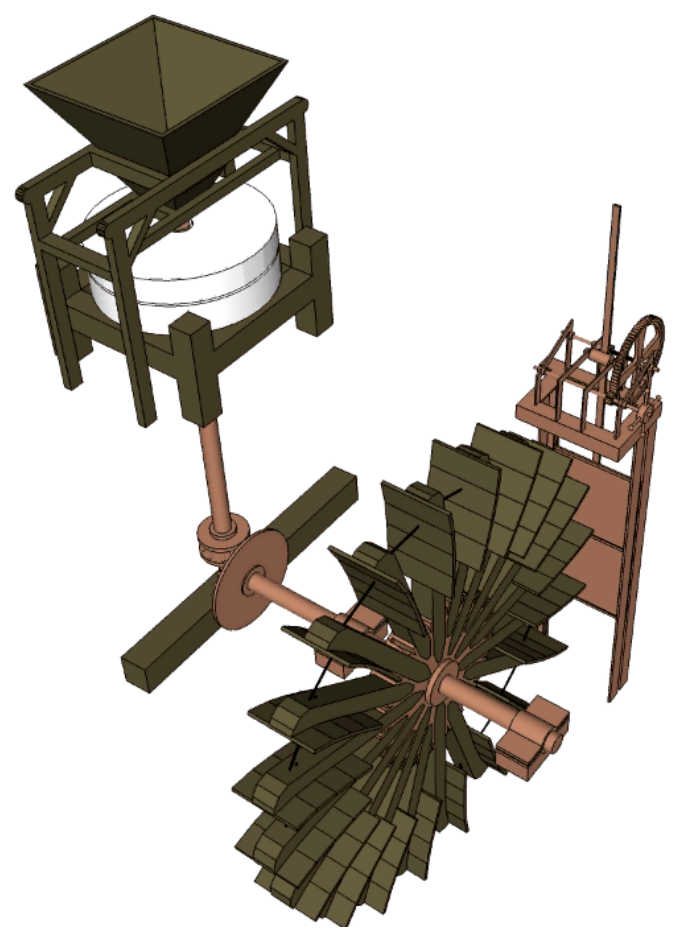

Figure 10: The grinding mechanism isolated from the mill for a better understanding of its operation

A more realistic representation can be useful for multimedia creation; it must include more advanced rendering aspects which involve to the Computational Fluid Dynamics. This broad reach goal is the most advanced challenge in ICT domain; its incorporation will allow to integrate currently available solutions for multimedia purposes in an interactive way; if resources would be available, it could be developed in the next future.

According to some recent tendencies, to illustrate the connection with socio-economic evolution of its environment, it is necessary to introduce human agents playing different roles able of interacting between them, as it occurs with avatars (by following similar patterns to those appearing in Second Life) and/or characters in videogames. These aspects concern to the exploitation of results to generate an economic return to these activities and we are not concerned with these topics.

\section{CONCLUSIONS AND FUTURE WORK}

In this work we have presented an architectural surveying of preindustrial installations for grinding cereals and a multilayered approach to the simulation of grinding processes in flour mills. To illustrate these processes we have performed an approach in different steps including a simplified representation of the socioeconomic and technological environment, an architectural surveying, a description of mechanisms and an illustration of their 
behavior in a simplified representation. This approach provides a support which can be useful not only for academic research linked to ICT contents, but to educational and entertainment purposes, also. In this way, we intend to contribute to the knowledge of past activities, the socio-economic articulation of a very rich historical and cultural environment, and the self-consciousness of an almost lost identity.

\section{ACKNOWLEDGEMENTS}

A precedent and much larger work was published as the book (I.SanJosé and J.J.Fernández-Martín, 2010) which corresponds to a research inside de PAHIS Program (Patrimonio Histórico), a project partially financed by the Junta de Castilla y León, Programa Operativo de Cooperación Transfronteriza España-Portugal (2007-2013), Fondo Europeo de Desarrollo Regional (FEDER), European Union. Aerial images arise from the National Plan of Aerial Ortophotography (PNOA) captured by the Instituto Tecnológico Agrario (ITACYL). Their contribution is grateful acknowledged.

\section{REFERENCES}

Creative City Challenges: Industrial heritage in fostering urban creative zones, 2014. Technical report, Hoje-Taastrup Kommune. Report co-funded by the Interreg IVB North-Sea Region Programme, the European Union and the Hoje-Taastrup Kommune.

Delgado, F. J., Martinez, R., Finat, J., Martinez, J., Puche, J. C. and Finat, F. J., 2013. Enhancing the reuse of digital resources for integrated systems to represent, understand and dynamize complex interactions in architectural cultural heritage environments. ISPRS Annals of Photogrammetry, Remote Sensing and Spatial Information Sciences 1(1), pp. 97-102.

I.SanJosé, J. and J.J.Fernández-Martín, 2010. Aceñas del Duero. Tordesillas, Toro y Zamora. Gráficas Lafalpoo. ISBN: 978-849718-620-9.

Keller, A., 1998. The twenty-one books of engineering and machines of Juanelo Turriano. Fundación Juanelo Turriano. A translation of the manuscript in the Biblioteca Nacional de España (Madrid) titled "Los veintiún libros de los ingenios y máquinas de Juanelo Turriano". 